\title{
The relation between endothelial dependent flow mediated dilation of the brachial artery and coronary collateral development - a cross sectional study
}

\author{
Aydan Ongun Ozdemir*1, Sadi Gulec ${ }^{1}$, Nihal Uslu ${ }^{2}$, Cansin Tulunay Kaya1, \\ Cagdas Ozdol ${ }^{1}$, Sibel Turhan ${ }^{1}$, Yusuf Atmaca ${ }^{1}$, Timucin Altin ${ }^{1}$ and Cetin Erol ${ }^{1}$
}

Address: ${ }^{1}$ Department of Cardiology, Ankara University School of Medicine, Ankara, Turkey and ${ }^{2}$ Department of Radiology, Baskent University School of Medicine, Ankara, Turkey

Email: Aydan Ongun Ozdemir* - aongun@msn.com; Sadi Gulec - gulec99@yahoo.com; Nihal Uslu - nihalt@baskent-ank.edu.tr; Cansin Tulunay Kaya - cansintulunay@gmail.com; Cagdas Ozdol - cagdas_2005@yahoo.com; Sibel Turhan - sblturhan@yahoo.com; Yusuf Atmaca - yusufatmaca1@yahoo.com; Timucin Altin - alitimaltin@yahoo.com; Cetin Erol - ctnerol@yahoo.com

* Corresponding author

Published: 15 June 2009

Cardiovascular Ultrasound 2009, 7:25 doi:10.1/86/|476-7|20-7-25
Received: 12 February 2009

Accepted: 15 June 2009

This article is available from: http://www.cardiovascularultrasound.com/content/7/I/25

(C) 2009 Ozdemir et al; licensee BioMed Central Ltd.

This is an Open Access article distributed under the terms of the Creative Commons Attribution License (http://creativecommons.org/licenses/by/2.0), which permits unrestricted use, distribution, and reproduction in any medium, provided the original work is properly cited.

\begin{abstract}
Background: Endothelial dysfunction is thought to be a potential mechanism for the decreased presence of coronary collaterals. The aim of the study was to investigate the association between systemic endothelial function and the extent of coronary collaterals.

Methods: We investigated the association between endothelial function assessed via flow mediated dilation (FMD) of the brachial artery following reactive hyperemia and the extent of coronary collaterals graded from 0 to 3 according to Rentrop classification in a cohort of 17I consecutive patients who had high grade coronary stenosis or occlusion on their angiograms.

Results: Mean age was 61 years and $75 \%$ were males. Of the 171 patients $88(51 \%)$ had well developed collaterals (grades of 2 or 3 ) whereas $83(49 \%)$ had impaired collateral development (grades of 0 or I). Patients with poor collaterals were significantly more likely to have diabetes ( $P$ $=0.00 \mathrm{I}$ ), but less likely to have used statins $(p=0.083)$. FMD measurements were not significantly different among good and poor collateral groups ( $11.5 \pm 5.6 \mathrm{vs}$. $10.4 \pm 6.2 \%$ respectively, $p=0.214$ ). Nitroglycerin mediated dilation was also similar ( $13.4 \pm 5.9$ vs. $12.8 \pm 6.5 \%, p=0.52 \mathrm{I})$.

Conclusion: No significant association was found between the extent of angiographically visible coronary collaterals and systemic endothelial function assessed by FMD of the brachial artery.
\end{abstract}

\section{Background}

Ischemic heart disease and myocardial infarction are the major causes of mortality and morbidity in industrialized countries. Well developed coronary collateral vessels have protective impacts such as limiting the size of myocardial infarction, reducing the incidence of heart failure and ventricular aneurysm, fewer cardiovascular events during fol- low-up and better survival rates [1-3]. However, there are significant differences in the degree of collateral development among individual patients [4]. Although clinical presentation with stable angina pectoris, presence of diabetes mellitus, the extent of coronary artery stenosis, the use of calcium channel blockers, statins, angiotensin converting enzyme inhibitors, elevated levels of C-reactive 
protein, and the number and function of endothelial progenitor cells were all suggested as potential determinants of collateral development, it is still unknown why some patients are capable of developing sufficient collateral circulation while others are not [5-8].

Recent studies have demonstrated that, nitric oxide (NO) bioavailability is critically important in collateral formation [9-11]. This led to a common perception that endothelial dysfunction is one of the potential mechanisms for the decreased presence of coronary collaterals. To date, however, the relation between endothelial function and collateral development has not been evaluated in clinical studies. Endothelial function can be assessed noninvasively via flow-mediated dilation (FMD) of the brachial artery using high resolution ultrasound $[12,13]$.

The current study was undertaken to assess whether endothelial function, measured by FMD, is associated with the extent of angiographically visible coronary collaterals in patients with high-grade coronary artery stenosis or occlusion.

\section{Methods \\ Study population}

All patients who underwent coronary angiography at our institution, and were found to have at least one major coronary occlusion, or a stenosis of $\geq 95 \%$ with Thrombolysis In Myocardial Infarction (TIMI) grade $\leq 1$ anterograde flow were screened for eligibility. Patients with diagnosis of acute coronary syndrome within the past 15 days, and patients who have undergone coronary angiography using right radial approach were excluded. Patients with a history of coronary bypass surgery were also excluded if (1) the operation has been done within the past 30 days, and (2) the distal aspect of the qualifying severely stenosed or occluded artery is supplied by the patent bypass graft.

All patients gave written informed consent and local ethics committee approved the study protocol.

\section{Coronary angiography and collateral scoring}

Coronary angiography was routinely performed by the Judkins method without the use of nitroglycerin. Percentage diameter stenosis was measured by using computerized quantitative angiography in a biplane mode (Philips DCI, Eindhoven, Netherlands). Two experienced interventional cardiologists (A.O.O and C.T.K) who were blinded to patient characteristics reviewed the angiograms and graded the coronary collaterals according to Rentrop classification [14]. In subjects with $>1$ collateral supplying the distal aspect of the diseased artery, the higher collateral grade was used. In subjects with $>1$ qualifying severely diseased vessel, the vessel with the higher collateral grade was chosen for analysis.
Intra- and inter-observer agreement of coronary collateral grades were determined from a random sample of 50 coronary angiograms (Kappa values were 0.935 for intra- and 0.845 for interobserver agreements; $p<0.001$ for both of them). Disagreements were resolved by an additional joint reading. Patients were divided into two groups according to their collateral grades. Group 1 consisted of patients with grade 0 or grade 1 collaterals (poor collateral group) and group 2 consisted of patients with grade 2 or grade 3 collaterals (good collateral group).

\section{Risk factor assessment}

Information about smoking, and alcohol consumption was collected through interview directly from the patients. Medical records were reviewed for reports of previous myocardial infarction, coronary artery bypass grafting, and percutaneous coronary intervention. Body mass index was calculated as weight $(\mathrm{kg})$ divided by height $\left(\mathrm{m}^{2}\right)$. Hypertension was defined as systolic blood pressure $\geq 140 \mathrm{~mm} \mathrm{Hg}$, diastolic blood pressure $\geq 90 \mathrm{~mm} \mathrm{Hg}$, or use of antihypertensive medication in the previous two weeks. Diabetes was defined as fasting blood glucose $\geq$ $126 \mathrm{mg} / \mathrm{dL}$, nonfasting blood glucose $\geq 200 \mathrm{mg} / \mathrm{dL}$, or use of antidiabetic medication in the previous two weeks. Diagnosis of acute coronary syndrome (ACS) was made according to the guidelines established by the American College of Cardiology and the American Heart Association [15]. Non-ACS patients had stable angina and/or positive stress tests.

Left ventricular ejection fraction was calculated by contrast venticulography using a standard area-length formula [16] $(n=65)$ or estimated by echocardiography when ventriculography was not performed $(n=106)$. Significant stenosis was defined as quantitatively measured diameter stenosis of $>70 \%$ in any of the major coronary arteries.

\section{Endothelium dependent and independent flow-mediated vasodilation (FMD)}

Endothelium dependent and independent flow-mediated dilation were performed by using a $13.0 \mathrm{MHz}$ linear array transducer (Vivid 7, Wipro GE Healtcare, GE Medical Systems Inc, Chicago, U.S.A) on the day after coronary angiography. After $12 \mathrm{~h}$ fasting (including caffeine, nicotine and alcohol), vascular measurements were performed in a quiet, temperature controlled $\left(22-24^{\circ} \mathrm{C}\right)$ room early in the morning ( $8 \mathrm{am}-10 \mathrm{am}$ ). Vasoactive medications were not stopped before FMD, but the morning doses were skipped on the examination day of FMD. After 15 min resting period in the supine position, the transducer was placed $4-5 \mathrm{~cm}$ above the elbow in the longitudinal section for the scanning of right brachial artery, then the basal diameter of brachial artery (from anterior intima to posterior intima) and flow velocity were measured. After- 
wards, sphygmomamometer cuff was placed on the upper arm, and inflated at $250 \mathrm{mmHg}$ for 4-5 min, and deflated abruptly. The flow velocity was recorded within $15 \mathrm{sec}-$ onds, and postocclusion artery diameters were taken at 60-120 seconds. After a 10 minutes resting interval, $5 \mathrm{mg}$ sublingual isosorbide dinitrate was administered, and brachial artery was scanned within the next 5 minutes. Brachial artery images were taken by two experienced observers (N.U and S.T) who were blinded to the collateral status of the patients. Diameter measurements were taken at the end of the diastole (timed by peak of $\mathrm{R}$ wave on electrocardiogram), which were calculated at least three times, and the average of these measurements were determined. Endothelium dependent and independent vasodilations were defined as the percent change in diameter compared with baseline (maximum diameter-baseline diameter/baseline diameterx100). Two sample cases of impaired, and preserved endothelium dependent FMD measurements have been demonstrated in Figures 1 and 2. Intra- and inter-observer variability of FMD measurements were determined from 40 randomly selected brachial artery images (Kappa values were 0.93 for intra- and 0.82 for inter-observer agreements; $p<0.001$ for both of them).

\section{Statistical analysis}

Data are expressed as mean \pm standard deviation for continuous variables, and number and percentage of subjects for categorical ones. Chi-square test with Yates correction was used to assess the significance of difference between categorical variables. When the values in the cells were not enough for chi-square test, Fischer's exact test was used. Continuous variables were compared by Student $t$-test or the Mann-Whitney rank sum test. Multivariable logistic regression analysis was used to adjust for the characteristics that were significant correlates of collateral development in the univariate analysis (with $p<0.1$ ) plus terms for age and gender due to their well-established association with coronary heart disease. Odds ratios (OR) with two-tailed $p$-values and 95\% confidence intervals (CI) were calculated as a measure of the association of the clinical, and therapy-related characteristics with collateral development. Statistical analyses were performed using SPSS software package (SPSS Inc., Chicago, Illinois, USA) version 16.0 for Windows and $p<0.05$ was considered statistically significant.

\section{Results}

A total of 257 patients met the angiographic criteria of having at least one major coronary occlusion, or a stenosis of $\geq 95 \%$ TIMI $\leq 1$ anterograde flow. Eighty-six were excluded for the following reasons: (1) acute coronary syndrome within the previous 15 days $(n=53)$; (2) failing to give informed consent ( $\mathrm{n}=15)$; (3) inadequate angiograms for collateral evaluation $(n=12)$; $(4)$ presence of occluded coronary artery that is supplied by the patent bypass graft $(n=6)$. Thus, the study group was comprised of 171 patients. Mean age of the study population was 61 years and $75 \%$ were males. Of the 171 patients, 88 (51\%) had well-developed collaterals (30 patients had grade 3 and 58 patients had grade 2 collaterals) whereas 83 (49\%) had impaired collateral development ( 37 patients had grade 1 collaterals; 46 patients had grade 0 collaterals). The prevalence of various demographic, angiographic and therapy related characteristics of the study subjects at the time of coronary angiography according to collateral clas-
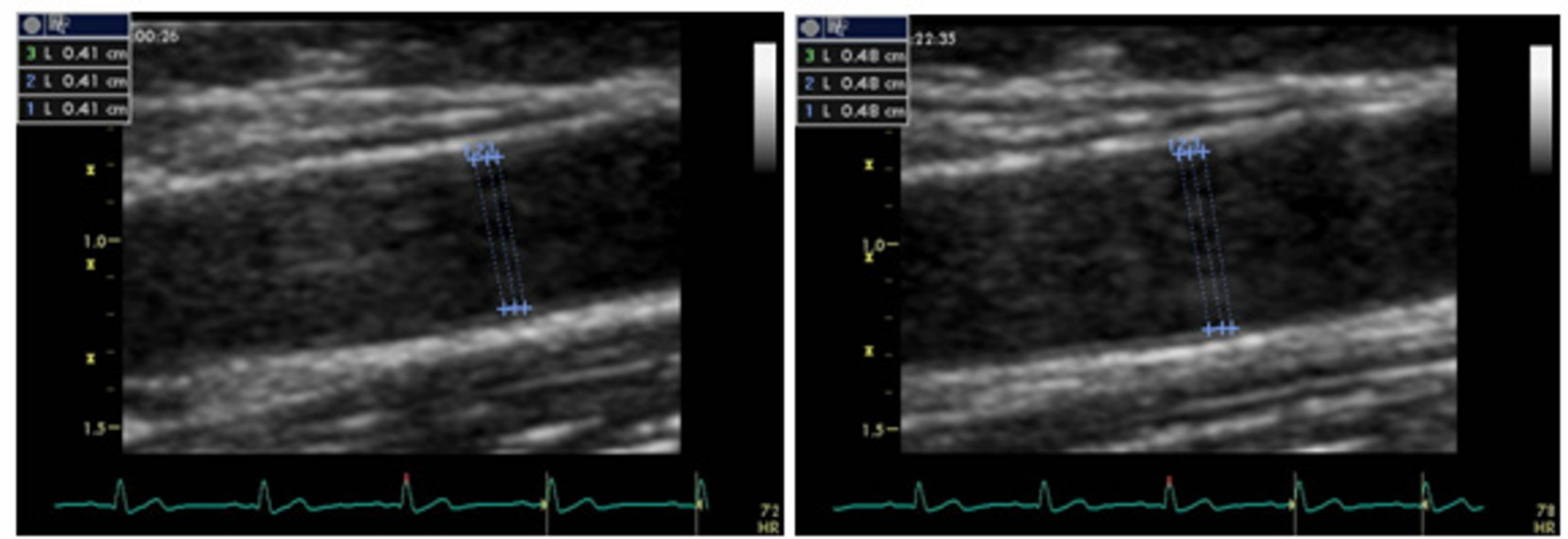

Figure I

Two-dimensional images of the brachial artery in a case with preserved endothelium dependent flow mediated dilation. Brachial artery measurements were made from anterior intima to posterior intima at baseline, and during reactive hyperaemia. Endothelium dependent vasodilation response was $17.1 \%$. 

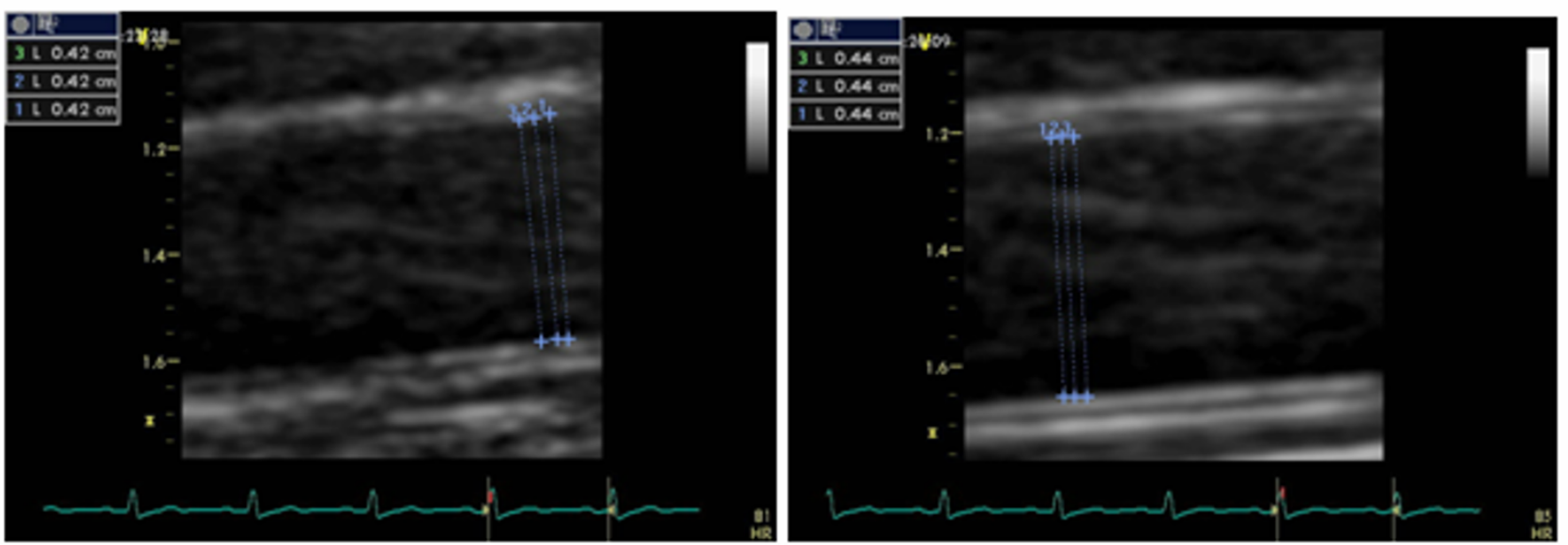

\section{Figure 2}

Two-dimensional images of the brachial artery in a case with impaired endothelium dependent flow mediated dilation. Brachial artery measurements were made from anterior intima to posterior intima at baseline, and during reactive hyperaemia. Endothelium dependent vasodilation response was $4.8 \%$.

sification are shown in Table 1 . Subjects with poor collaterals were significantly more likely to have diabetes mellitus $(p=0.001)$ and less likely to have used statins ( $p$ $=0.083)$. The prevalence of all other cardiovascular risk factors and use of medications were similar at different levels of collaterals.

Mean FMD of the study population was $10.9 \pm 5.9 \%$, and mean nitroglycerin mediated dilation was $13.1 \pm 6.2 \%$. Figure 3 and 4 shows the mean FMD values according to categories of Rentrop collateral classification. Endothelium dependent vasodilation response was not significantly different among good and poor collateral groups $(11.5 \pm 5.6 \%$ vs. $10.4 \pm 6.2 \%, p=0.214)$. Nitroglycerin mediated dilation was also similar $(13.4 \pm 5.9 \%$ vs. 12.8 $\pm 6.5 \%, p=0.521)$. We have then performed a subgroup analysis by classifying patients into 4 quartiles according to FMD results, and found that the presence of good collaterals did not differ in the first through fourth quartiles $(p=0.42)$. Also, the $\mathrm{p}$ value of FMD responses between quartiles 1 and 4 was still not significant [First quartile: FMD<6.6\%, $(\mathrm{n}=42), 43 \%$; fourth quartile: FMD $>14.7 \%$, $(\mathrm{n}=41), 57 \% ; p=0.13]$.

In multivariable model, diabetic patients were 2.9 times more likely to have poor collaterals than non-diabetics (95\% CI: $1.6-5.7, p=0.001)$, and patients who were not taking statins were 2 times more likely to have poor collaterals than patients taking statins (95\% CI: 1.01-3.9, $p=$ $0.048)$.

\section{Discussion}

In this cohort of 171 patients with significant coronary artery disease we failed to find any association between FMD of the brachial artery and the extent of angiographically visible coronary collaterals. To the best of our knowledge this is the first study evaluating the relation between endothelial function and collateral formation.

Previous studies repeatedly demonstrated that nitric oxide had a pivotal role in the regulation of collateral artery development [17-19]. It has been suggested, accordingly, that endothelial dysfunction of which decreased vasodilator activity of NO is a hallmark, could be one of the potential mechanisms for the decreased presence of coronary collaterals.

One possible explanation for our negative finding is that FMD of the brachial artery examines conduit vessel response rather than the response of resistance vessels such as coronary and collateral arteries [12]. In oppose of this assumption however, many studies have demonstrated that impaired FMD is significantly associated with coronary endothelial dysfunction [20-22]. On the other hand, Anderson et al. recently showed that FMD of the brachial artery was not very sensitive (49\% sensitivity) at the cut off value $>3 \%$ for the detection of coronary endothelial dysfunction and speculated FMD could not be used for the prediction of the magnitude of the coronary vasodilator response [23]. Fairly high FMD values noted in the present trial $(10.9 \pm 5.9 \%)$ may therefore help to explain why FMD failed to correlate with collateral score. 
Table I: Characteristics of the subjects according to collateral groups

\begin{tabular}{|c|c|c|c|}
\hline Variables & $\begin{array}{l}\text { Poor collateral } \\
\quad(n=83)\end{array}$ & $\begin{array}{l}\text { Good collateral } \\
(n=88)\end{array}$ & p value \\
\hline Age (years) & $61 \pm 10$ & $61 \pm 11$ & 0.738 \\
\hline Gender, males (\%) & $65(78)$ & $64(73)$ & 0.396 \\
\hline Diabetes mellitus (\%) & $46(55)$ & $27(3 \mathrm{I})$ & 0.001 \\
\hline Hypertension (\%) & $49(59)$ & $56(64)$ & 0.537 \\
\hline Current smokers (\%) & $41(49)$ & $39(44)$ & 0.506 \\
\hline Daily alcohol consumption (\%) & $3(3.4)$ & $3(3.6)$ & 1.0 \\
\hline $\mathrm{BMI}, \mathrm{kg} / \mathrm{m}^{2}$ & $28 \pm 4$ & $27 \pm 4$ & 0.292 \\
\hline Previous MI (\%) & $55(66)$ & $53(60)$ & 0.413 \\
\hline Previous CABG (\%) & $14(17)$ & $12(14)$ & 0.556 \\
\hline Total cholesterol, mg/dL & $180 \pm 40$ & $179 \pm 44$ & 0.828 \\
\hline $\mathrm{LDL}-\mathrm{C}, \mathrm{mg} / \mathrm{dL}$ & $109 \pm 34$ & $107 \pm 40$ & 0.700 \\
\hline $\mathrm{HDL}-\mathrm{C}, \mathrm{mg} / \mathrm{dL}$ & $41 \pm 10$ & $39 \pm 9$ & 0.285 \\
\hline Triglycerides, mg/dL & $152 \pm 91$ & $165 \pm 80$ & 0.168 \\
\hline Creatinine, $\mathrm{mg} / \mathrm{dL}$ & $\mathrm{I} . \mathrm{I} \pm 0.3$ & $1.2 \pm 0.9$ & 0.607 \\
\hline LV ejection fraction, \% & $46 \pm 13$ & $49 \pm 13$ & 0.182 \\
\hline Number of vessels with significant stenosis (\%) & & & 0.995 \\
\hline I vessel & $27(30.7)$ & $25(30.1)$ & \\
\hline 2 vessel & $26(29.5)$ & $25(30.1)$ & \\
\hline 3 vessel & $35(39.8)$ & $33(39.8)$ & \\
\hline Lesion location (\%) & & & 0.154 \\
\hline Left anterior descending artery & $64(72.7)$ & $66(79.5)$ & \\
\hline Circumflex artery & $53(60.2)$ & $53(63.9)$ & \\
\hline Right coronary artery & $67(76.1)$ & $55(66.3)$ & \\
\hline \multicolumn{4}{|l|}{ Cardiovascular medications (\%) } \\
\hline Aspirin & $72(87)$ & $74(84)$ & 0.623 \\
\hline Beta-blockers & $57(69)$ & $56(64)$ & 0.487 \\
\hline Calcium channel blockers & $5(6)$ & $11(13)$ & 0.146 \\
\hline ACE-Is or ARBs & $57(69)$ & $62(71)$ & 0.800 \\
\hline Nitrates & $28(34)$ & $35(40)$ & 0.413 \\
\hline Statins & $50(60)$ & $64(73)$ & 0.083 \\
\hline
\end{tabular}

ACE-I, angiotensin converting enzyme inhibitor; ARB, angiotensin receptor blocker; BMI, body mass index; CABG, coronary artery bypass grafting; HDL-C, high density lipoprotein cholesterol; LDL-C, low density lipoprotein cholesterol; LV, left ventricular; MI, myocardial infarction

Another explanation for the lack of association between FMD and collateral development could be the drug effect. It has been reported that vasoactive medications have a significant effect on FMD response of brachial artery to reactive hyperemia so that it is recommended to stop these drugs at least four half-lives before FMD measurements $[12,13]$. Withdrawal of all vasoactive drugs in such patients with significant coronary disease, however, does not seem to be ethical. Moreover, many of these drugs were suggested to be a significant determinant of collateral formation as well [24-26] and study patients were taking them on the day of collateral evaluation. Thus we did opt to keep the medication as is. While interpreting our data however, it should be kept in mind that the responses of brachial and collateral arteries to vasoactive medications would not necessarily be the same. Indeed, vasodilator response of collateral arteries to pharmacological agents have recently been shown to be different from that of coronary arteries $[27,28]$.
Recent data suggest that vasodilator role of $\mathrm{NO}$ in collateral artery development may vary depending on the duration of coronary occlusion. In an animal model of collateralogenesis it has been shown that a duration of 9 months is needed for the development of endothelium dependent relaxation mediated primarily by NO [29]. Since our data did not provide us any information about the time of coronary stenosis/occlusion, it is possible that time needed for NO to show its full vasodilatory effect has not been completed in at least some of our patients. This may have influenced our results.

It is also possible that the vasodilatory role of $\mathrm{NO}$ in collateral arteries might be replaced by other vasoactive influences like prostaglandins which were shown to have significant vasodilating effect on collateral vessels [30].

In conclusion, our data suggest that FMD may not be the mirror of coronary circulation and the lack of a significant relation between extent of coronary collaterals may be different from its relation of coronary artery disease extent. 


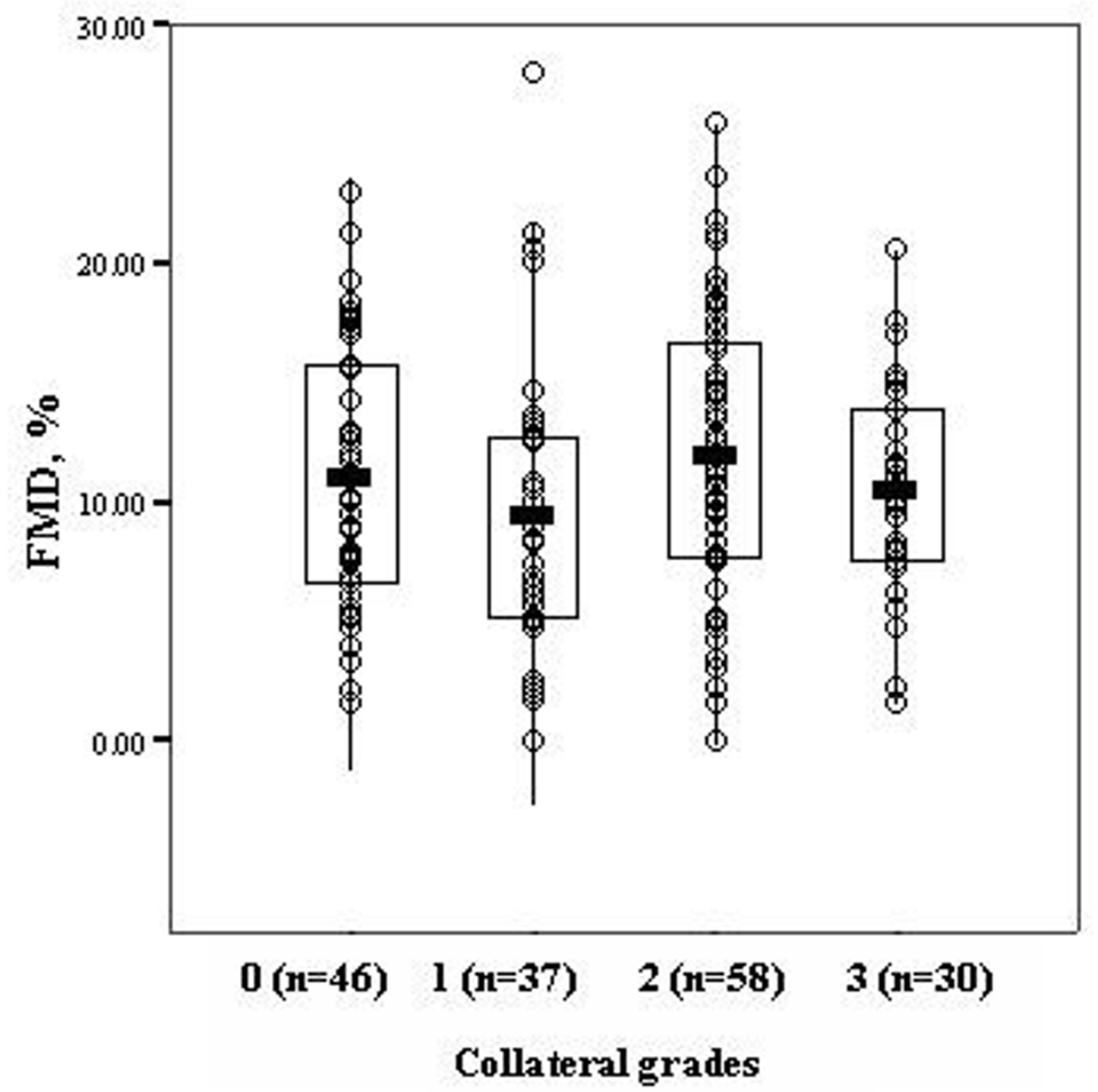

\section{Figure 3}

Flow mediated dilation values according to categories of the Rentrop collateral classification. Boxes cover the $95 \%$ confidence intervals where the line bisecting the box depicting the mean.

\section{Limitations}

The potential limitations of the present study are the relatively small sample size and the cross sectional study design. Despite this, all demographic and clinical variables were collected systematically using a prespecified data collection form and the prospectively collected angiographic, and laboratory data did provide us the opportunity to control for most, if not all of the potential confounders. Previous data have suggested that FMD is impaired in patients with coronary artery disease. Mean FMD values of $10.9 \pm 5.9 \%$ in this cohort may, thus, be considered as unexpected. Exclusion of patients with acute coronary syndrome, high rate of statin use and performing FMD procedure without stopping the vasoactive medications may account for the fairly high FMD values observed in this trial. Nevertheless, our finding that FMD is not related with collateral formation may not be extrap- olated to coronary artery disease patients with impaired FMD values. Moreover, manual ultrasonically assessment of brachial endothelial function is a noisy measurement with critical technical and interpretative limitations. It would be interesting to use a commercially available system for the automatic assessment of brachial FMD; which could be a more robust and reproducible tool.

It might be debated that Cohen-Rentrop classification is semiquantitative and might not represent the collaterals as precisely as fractional flow reserve (FFR) which is currently the gold standard for determining the presence and degree of collaterals. Although hemodynamic assessment is superior to angiographic assessment in grading collateral circulation, close correlation between Cohen-Rentrop classification and collateral FFR has been documented before [31]. Based on these data we preferred to use this 


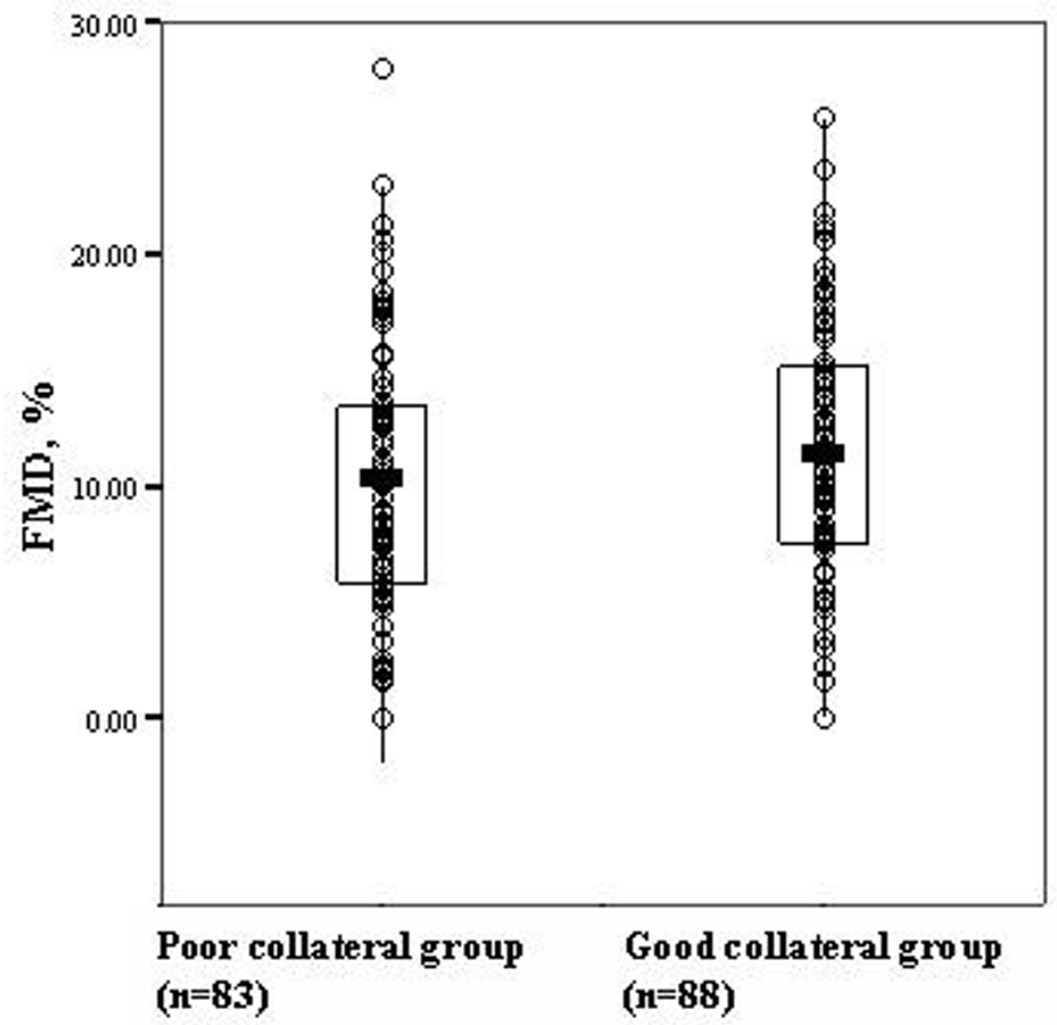

Figure 4

Distribution of flow mediated dilation values by collateral groups. Boxes cover the $95 \%$ confidence intervals where the line bisecting the box depicting the mean.

widely used, practical angiographic method to grade collateral circulation.

Finally, FMD values may not reflect the true, steady state FMD values as they may be affected by the coronary angiography. However, although some reports suggested percutaneous coronary intervention procedures had an effect on FMD measurements, this was not confirmed for diagnostic coronary angiography [32].

\section{Conclusion}

Our findings indicate that systemic endothelial function assessed via brachial artery FMD is not associated with the extent of angiographically visible coronary collateral development. Further studies are needed to evaluate the role of endothelial function on collateral formation.

\section{Competing interests}

The authors declare that they have no competing interests.

\section{Authors' contributions}

AOO collected data, designed and drafted the manuscript. NU, CTK, ST helped to collect data and draft the manuscript. CO, TA participated in the design of the article and performed the statistical analysis. SG, YA, CE revised the article. All authors read and approved the final manuscript.

\section{Acknowledgements}

The authors wish to thank Mrs. Selda Yildirim for her expert assistance as a research nurse.

\section{References}

I. Cohen M, Rentrop KP: Limitation of myocardial ischemia by collateral circulation during sudden controlled coronary artery occlusion in human subjects: a prospective study. Circulation 1986, 74:469-476.

2. Kodama K, Kusuoka H, Sakai A, Adachi T, Hasegawa S, Ueda $Y$, Mishima M, Hori M, Kamada T, Inoue M, Hirayama A: Collateral channels that develop after an acute myocardial infarction prevent subsequent left ventricular dilation. J Am Coll Cardiol 1996, 27: II33-1139. 
3. Hirai T, Fujita M, Nakajima $\mathrm{H}$, Asanoi $\mathrm{H}$, Yamanishi $\mathrm{K}$, Ohno A, Sasayama S: Importance of collateral circulation for prevention of left ventricular aneurysm formation in acute myocardial infarction. Circulation 1989, 79:79|-796.

4. Pohl T, Seiler C, Bilinger M, Herren E, Wustmann K, Mehta H, Windecker S, Eberli FR, Meier B: Frequency distribution of collateral flow and factors influencing collateral channel development. Functional collateral channel measurement in $\mathbf{4 5 0}$ patients with coronary artery disease. J Am Coll Cardiol 200I, 38:1872-1878

5. Kilian JG, Keech A, Adams MR, Celermajer DS: Coronary collateralization: determinants of adequate distal vessel filling after arterial occlusion. Coron Artery Dis 2002, I 3:155-159.

6. Paurati I, Kimmelstiel C, Rand W, Karas RH: Statin use is associated with enhanced collateralization of severely diseased coronary arteries. Am Heart J 2003, I46:876-88I.

7. Gulec S, Ozdemir AO, Maradit-Kremers H, Dincer I, Atmaca Y, Erol $\mathrm{C}$ : Elevated levels of C-reactive protein are associated with impaired coronary collateral development. Eur J Clin Invest 2006, 36:369-375.

8. Matsuo $Y$, Imanishi T, Hayashi $Y$, Tomobuchi $Y$, Kubo T, Hano T, Akasaka $T$ : The effect of endothelial progenitor cells on the development of collateral formation in patients with coronary artery disease. Intern Med 2008, 47:127-134.

9. Toyota E, Matsunaga T, Chilian WM: Myocardial angiogenesis. Mol Cell Biochem 2004, 264:35-44.

10. Schaper W, Scholz D: Factors regulating arteriogenesis. Arterioscler Thromb Vasc Biol 2003, 23: I I 43-I I II.

II. Gulec S, Karabulut H, Ozdemir AO, Ozdol C, Turhan S, Altin A, Tutar E, Genc Y, Erol C: Glu298Asp polymorphism of the eNOS gene is associated with coronary collateral development. Atherosclerosis 2008, 198:354-359.

12. Moens AL, Goovaerts I, Claeys MJ, Vrints CJ: Flow-mediated vasodilation. A diagnostic instrument, or an experimenta tool? Chest 2005, 127:2254-2263.

13. Coretti MC, Anderson TJ, Benjamin EJ, Celermajer D, Charbonneau F, Creager MA, Deanfield J, Drexler H, Gerhard-Herman M, Herrington D, Vallance P, Vita J, Vogel R: Guidelines for the ultrasound assessment of endothelial-dependent flow-mediated vasodilation of the brachial artery: a report of the International Brachial Artery Reactivity Task Force. J Am Coll Cardiol 2002, 39:257-265.

I4. Rentrop KP, Cohen M, Blanke H, Phillips RA: Changes in collateral channel filling immediately after controlled coronary artery occlusion by an angioplasty balloon in human subjects. J Am Coll Cardiol 1 985, 5:587-592.

15. Anderson JL, Adams CD, Antman EM, et al.: ACC/AHA 2007 guidelines for the management of patients with unstable angina/non ST-elevation myocardial infarction: a report of the American College of Cardiology/American Heart Association Task Force on Practice Guidelines (Writing Committee to Revise the 2002 Guidelines for the Management of Patients With Unstable Angina/Non ST-Elevation Myocardial Infarction). Circulation 2007, I I 6:e I 48-e304.

16. Dodge HT, Sandler H, Baxley WA, Hawley RR: Usefulness and limitations of radiographic methods for determining left ventricular volume. Am J Cardiol 1966, 18:10-24.

17. Buckwalter JB, Curtis VC, Valic Z, Ruble SB, Clifford PS: Endogenous vascular remodeling in ischemic skeletal muscle: a role for nitric oxide. J Appl Physiol 2003, 94:935-940.

18. Matsunaga T, Wartlier DC, Weihrauch DW, Moniz M, Tessmer J, Chilian WM: Ischemia-induced coronary collateral growth is dependent on vascular endothelial growth factor and nitric oxide. Circulation 2000, 102:3098-3103.

19. Lloyd PG, Yang TH, Terjung RL: Arteriogenesis and angiogenesis in rat ischemic hindlimb: role of nitric oxide. Am J Physiol Heart Circ Physiol 200I, 28I(6): $\mathrm{H} 2528-\mathrm{H} 2538$

20. Neunteufl T, Katzenschlager R, Hassan A, Klaar U, Schwarzacher S, Glogar D, Bauer P, Weidinger F: Systemic endothelial dysfunction is related to the extent and severity of coronary artery disease. Atherosclerosis 1997, I 29: I| |- | |8.

21. Takase B, Uehata A, Akima T, Nagai T, Nishioka T, Hamabe A, Satomura K, Ohsuzu F, Kurita A: Endothelium-dependent flowmediated vasodilation in coronary and brachial arteries in suspected coronary artery disease. Am J Cardiol 1998, 82:1535-1539.
22. Playford DA, Watts GF: Special article: non-invasive measurement of endothelial function. Clin Exp Pharmacol Physiol 1998, 25:640-643.

23. Anderson TJ, Uehata A, Gerhard MD, Meredith IT, Knab S, Delagrange D, Lieberman EH, Ganz P, Creager MA, Yeung AC, et al: Close relation of endothelial function in the human coronary and peripheral circulations. J Am Coll Cardiol I995, 26: I235-I 24 I.

24. Jolly SR, Hardman HF, Gross GJ: Comparison of two dihydropyridine calcium antagonists on coronary collateral blood flow in acute myocardial ischemia. J Pharmacol Exp Ther 1981, 217:20-25.

25. Aoki M, Sakai K, Koyanagi S, Takeshita A, Nakamura M: Effect of nitroglycerin on coronary collateral function during exercise evaluated by quantitative analysis of thallium-20 I single photon emission computed tomography. Am Heart J |99I, I21:1361-1366.

26. Altin T, Kilickap M, Tutar E, Turhan S, Atmaca Y, Gulec S, Oral D, Erol $C$ : The relationship of chronic angiotensin converting enzyme inhibitor use and coronary collateral vessel development. Int Heart / 2007, 48:435-442.

27. Rapps JA, Jones AW, Sturek M, Magliola L, Parker JL: Mechanisms of altered contractile responses to vasopressin and endothelin in canine coronary collateral arteries. Circulation 1997, 95:23I-239.

28. Altman J, Dulas D, Pavek T, Laxson DD, Homans DC, Bache RJ: Endothelial function in well-developed canine coronary collateral vessels. Am J Physiol 1993, 264:H567-572.

29. Rapps JA, Myers PR, Zhong Q, Parker JL: Development of endothelium-dependent relaxation in canine coronary collateral arteries. Circulation 1998, 98:1675-1683.

30. Altman J, Dulas D, Bache RJ: Effect of cyclooxygenase blockade on blood flow through well-developed coronary collateral vessels. Circ Res 1992, 70:1091-1098.

31. Seiler C, Fleisch M, Garachemani A, Meier B: Coronary collateral quantitation in patients with coronary artery disease using intravascular flow velocity or pressure measurements. J Am Coll Cardiol 1998, 32:1272-1279.

32. Warnholtz A, Ostad MA, Heitzer T, Goldmann BU, Nowak G, Munzel T: Effect of tirofiban on percutaneous coronary intervention-induced endothelial dysfunction in patients with stable coronary artery disease. Am J Cardiol 2005, 95:20-23.
Publish with Biomed Central and every scientist can read your work free of charge

"BioMed Central will be the most significant development for disseminating the results of biomedical research in our lifetime. "

Sir Paul Nurse, Cancer Research UK

Your research papers will be:

- available free of charge to the entire biomedical community

- peer reviewed and published immediately upon acceptance

- cited in PubMed and archived on PubMed Central

- yours - you keep the copyright
BioMedcentral 